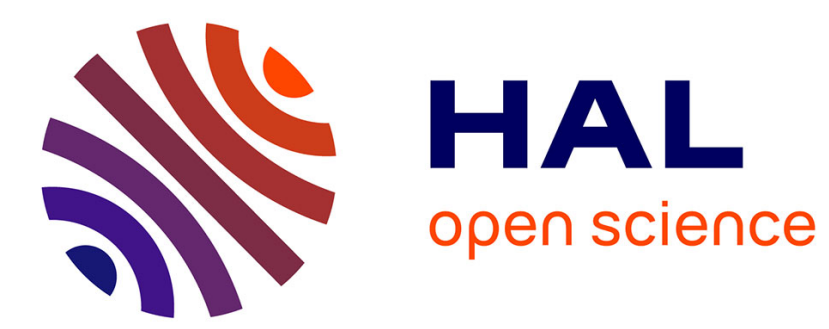

\title{
Scrutinizing Open Government Data to Understand Patterns in eGovernment Uptake
}

Helle Zinner Henriksen

\section{To cite this version:}

Helle Zinner Henriksen. Scrutinizing Open Government Data to Understand Patterns in eGovernment Uptake. 14th International Conference on Electronic Government (EGOV), Aug 2015, Thessaloniki, Greece. pp.144-155, 10.1007/978-3-319-22479-4_11 . hal-01412246

\section{HAL Id: hal-01412246 \\ https://hal.science/hal-01412246}

Submitted on 8 Dec 2016

HAL is a multi-disciplinary open access archive for the deposit and dissemination of scientific research documents, whether they are published or not. The documents may come from teaching and research institutions in France or abroad, or from public or private research centers.
L'archive ouverte pluridisciplinaire HAL, est destinée au dépôt et à la diffusion de documents scientifiques de niveau recherche, publiés ou non, émanant des établissements d'enseignement et de recherche français ou étrangers, des laboratoires publics ou privés. 


\title{
Scrutinizing Open Government Data to Understand Patterns in eGovernment Uptake
}

\author{
Helle Zinner Henriksen \\ Copenhagen Business School \& University of Agder \\ hzh.itmecbs.dk
}

\begin{abstract}
Research on open government data focuses mainly on standards for publishing data and access to data. In this study of the uptake of Digital Post in Denmark open data is applied in the analysis of the course of events leading up to the implementation of the mandatory digital mail-box. The study reflects on the impact of communication via local print media and discusses the body of literature which focuses on print media as a vehicle for communication to citizens. The study opens for a discussion of how open government data-sets give new opportunities for generating scholarly insights but also how it can challenge the position of researchers.
\end{abstract}

Keywords: open data, print media, mandatory e-government services

\section{Introduction}

Digital self-services in public sector have been discussed extensively in the egovernment literature for more than a decade. Empirical studies have explored various angles of usability [26], impact, transformation [20], and access [13] just to mention a few. The digital self-services have been seen as a tool of efficiency in public administration and further an alternative channel to service provision and communication with public sector. Most e-government studies are optimistic and enthusiastic about the digital agenda. However, some contributions have raised concerns and skepticism [16; 20]. Access or digital divide [19] was one of the core concerns and counter argument to the more techno-optimistic accounts in the early stage of academic research on digital self-services provided by public sector. The first contributions in the digital divide literature focused on those groups in society without access to computers and Internet [19; 12]. With the fast diffusion of Internet in society the discussion shifted from the have/have-not dichotomy to a more multifaceted view involving social, institutional and political factors along with the availability of technology [12]. Another dimension in the digital divide debate which has pinpointed potential weaknesses to the digital agenda relates to digital literacy [4]. With the massive diffusion of Internet to the majority of the grown population in the Western societies the core issue in the ability to use digital self-services is not access to the services but rather the ability to read and understand the content of the digital services. Administrative literacy is crucial [4]. The issue of administrative literacy has been highlighted in the digital immigrant/ digital native discussion where it has been argued that the digital

adfa, p. 1, 2011.

(C) Springer-Verlag Berlin Heidelberg 2011 
natives have limited digital capabilities [25]. These factors can influence the uptake and use of the digital self-services [25] but have on the other hand not hindered a constant development and implementation of digital self-services among governments throughout the globe. From a citizen perspective the mitigating circumstances have been that uses of digital self-services so far have been voluntary. The reported study presents an initiative which makes eGovernment use mandatory unless the citizen actively opts out. Danish Citizens are digital by default. The digital by default strategy is the final goal of 15 years of digital strategies for the Danish public sector. It is materialized in a mandatory digital mailbox for all citizens +15 years of age. The digital mailbox will be used for all communication from public sector to a citizen and does replace most window envelopes from public sector to citizens. It is in principle a oneway communication from government to citizens which in some case initiates further interaction and thus represents the first step in digital self-service e.g. rectification or correction of tax statement, confirmation of waiting list, or application for subsidies.

The primary objective of this article is to initiate a discussion about the potential of using open government data-sets in (eGovernment) research and furthermore the implications of getting pre-packaged data-sets for research purposes. To illustrate the discussion the case of uptake of the digital mailbox in Denmark is presented. The uptake is analyzed using open data-sets from the Agency of Digitization combined with print media content. Open government data has received much attention in the eGovernment research community. Focus has mainly been on the overall PSI agenda [14] or the standards for publishing data and access to data [15]. The use of open data for the purpose of analyzing Governments' own actions has received little attention. And to the authors knowledge the implications of open data for scholarly knowledge generation has not received any attention yet. To set the scene for the analysis another type of open data is included. That is open data on the Parliamentary process. Data is included to illustrate the political discussions prior to the implementation of the law. The next section presents the content of these political discussions. Section 3 provides an introduction to media frames which is applied as the analytical lens of the open data-sets. Section 4 presents the research method, including handling of data, graphical illustrations of data, and interpretations of data. The final section offers some concluding remarks.

\section{The mandatory public mail box}

In the Danish context some digital citizen services have been implemented via direct legislation. In line with this strategy the Minister of Finance in 2012 proposed a law on mandatory digital post for all Danish citizens to the Danish parliament. The proposal was part of the implementation of a public digitization strategy outlined in collaboration between municipalities and central government [8]. The overall objective was to achieve a goal of making $80 \%$ of all communication between citizens and public sector digital before end of 2015. The strategy stipulates "End of paper forms and letters: In their busy working life Danes should not waste their time filling paper forms at the local town hall. Tax-money should not be used on stamps and handling 
of paper, when we have digital solutions which can solve things more efficient." [8, p.3]. The quoted passage from the digitization strategy reflects the optimistic discourse presented in a large share of annual reports from International associations such as WEF, UN, and OECD and the e-government literature including proceedings of the EGOV conferences over the years.

\subsection{The preparation and passing of the law}

In the Danish context the process of legislation is highly documented. Transcripts of Parliamentary sessions and documentation such as minutes from meetings, responses from hearings, and other relevant data from the preparation and negotiation in parliament is open and easily searchable via a portal hosted by the Danish Parliament.

The reading of the open archives of the Danish Parliament illustrates that throughout the parliamentary discussions and approval of the law elected politicians and associations, which had contributed with responses via public hearings, primarily discussed three themes: the possibility of opting out of the mandatory digital post, privacy and security challenges, and the infrastructure supporting the digital post. The infrastructure consists of a digital signature, the "NemID" and a postbox "e-boks". The infrastructure is hosted by a private provider "Nets" owned by two US based hedge funds and a Danish pension fund, which has a minor share. Some parliamentarians viewed the private ownership problematic due to the handling of sensitive and confidential information about citizens. However, the core of the discussion related to the possibility of opting out from the digital postbox. In order to accommodate for consensus in the Parliament the final law has specific paragraphs about how to opt out. The law and its respective documents reflect none discussions or debates about the financial rationale behind the implementation of mandatory digital mail for all citizens. It appears that there is a consensus among the elected politicians that the initiative is financially viable and reasonable in general. The political consensus is in line with other studies on eGovernment diffusion [18]. The passing of the law was subject to little discussion considering its far reaching implications for each and every Danish citizen +15 years. And further has huge implications for the daily routines of civil servants [2]. The law on mandatory digital post came into force on November 1st 2014. It was the Agency of Digitization which was in charge of the overall implementation of the law. To stimulate the competition among municipalities the agency created a high degree of transparency in the adoption process. Each week the Agency of Digitization published statistics on number of citizens who had signed up for the digital post box and also number of citizens who had asked for exemption from the law. Municipalities have the most direct interaction with citizens and were in charge of getting citizens on board through local initiatives and campaigns. It became a measure in itself for municipalities to harvest the honor of being the winner of the week by being the "weekly top performer" measured by the increase in percentage of citizen enrollment or to be among the Top 5 digital municipalities.

The Agency of Digitization prepared campaigning material for municipalities and orchestrated campaigns to promote the Digital Post prior to November 1st. Templates for Web-banners, pamphlets and flyers, posters, and other material was devel- 
oped and distributed to municipalities. The effects of information campaigns are well researched in social science and leave a mixed picture of the effect of the hypodermic model [9]. The hypodermic model suggests that mass media have direct and powerful effects on a mass audience [24]. The model fundamentally suggests that citizens are passive recipients who are easy to manipulate [9] and that media are powerful instruments to create awareness of innovations among diverse groups of people [24].

\section{Media as vehicles of public information}

Though there has been a decrease in the circulation number of newspapers there is still a strong interest in news among citizens [23]. The most recent cross-country analysis of media use reflects that Danes are consuming news on a daily basis. News is presented mainly via TV but also newspapers both printed and online whereas social media as a channel for news plays a less prominent role [23]. Media is a cornerstone in society and shape public opinion by their framing of events [7]. The framing is driven by various factors and represents "interpretive packages" [10]. Gamson and Modigliani [10] refer to media packages which "can be conceived as a set of interpretive packages that give meaning to an issue. The package has an internal structure. And its core is a central organizing idea, or frame, for making sense of relevant events," (p. 3).

Table 1. Components of frames

\begin{tabular}{|l|l|}
\hline Framing devices & How to think about the issue \\
\hline Metaphors & $\begin{array}{l}\text { Imagined events which are intended to illuminate and enhance } \\
\text { our understanding through powerful illustrations }\end{array}$ \\
\hline Exemplars & Real events of the past or present \\
\hline Catchphrases & The capture of essence in a single theme statement or slogan \\
\hline Depictions & $\begin{array}{l}\text { Characteristics in a particular fashion through some colorful } \\
\text { string of modifiers }\end{array}$ \\
\hline Visual images & Icons or other visual images \\
\hline Reasoning devices & What should be done about the issue \\
\hline Roots & Analysis of the causal dynamics underlying the strip of events \\
\hline Consequences & $\begin{array}{l}\text { Analysis of the consequences that will flow from different } \\
\text { actions or interventions. Focus can be on the short or long term } \\
\text { consequences }\end{array}$ \\
\hline $\begin{array}{l}\text { Appeals to princi- } \\
\text { ple }\end{array}$ & $\begin{array}{l}\text { Rely on characteristic moral appeals and uphold certain general } \\
\text { precepts }\end{array}$ \\
\hline
\end{tabular}

Adapted from Gamson and Modigliani [10]

The framing and media packages play a central role in the construction of the social reality. The media analysis as presented by $[7 ; 9 ; 10]$ has as its starting point the framing. It is referred to as interpretive packages. Macro level issues in society have several interpretive packages each representing for example ideological or political 
stances. As such they represent the key dialectical principle of debate in the public sphere - every claim tends to generate a counter-claim [11]. The interpretive package consists of an overall frame and position that defines it (i.e. roots, consequences, and appeals to principles). A central part of the construction of the social reality relates to the lexical choice [11]. "The lexical choice and discursive practices are central components on how issues are rhetorically constructed and 'framed' and how in turn particular messages/meanings are conveyed and boundaries set for public understanding and public interpretation..." [11, p. 10].

The framing and the lexical choice constitutes the representation of for example digital signature. Representation requires that the communicator takes a position. The far reaching example is the Orwellian news-speak from the 1984 novel. In the IT context the positions often range from the cyber-optimists to the cyber-pessimists with the cyber-realists in between [19]. The 'spin' to the framing of news stories appear to differ depending on the context [11] and from the reading of the sample of articles included in the analysis on the communication of Digital Post in local newspapers it appears that the content of the often very brief articles most often is informative rather than opinionated.

Media analysis has received attention within the area of public sector IT and policies. Examples include a critical analysis of Swedish ICT policy visions [21] and a content analysis of political speeches related to digital divide [17]. Kvasny and Truex [17] identify how the term digital divide is shifted to digital opportunities. They observe how the (US) presidential speeches present technology as a "magical force" which is a means for progress. They argue that governments play an important role in popularizing technology terms and in giving meaning to them. Yildiz and Saylam [27] reach similar conclusions in their content analysis of e-government discourses in Turkish newspapers. Yildiz and Saylam [27] suggest that "Media use for discourse production and reinforcement is critical because media outlets can be very effective in legitimizing initiatives such as e-government."

\section{Research method, data collection, and data representation}

The Agency of Digitization has since 2011 published data on uptake per municipality on a weekly basis [1]. The data is published as open data in Excel format and can be downloaded at their web-site. The open data was used to identify patterns in uptake across the five Danish regions. The five Danish regions differ in population and number of municipalities. The "Region Hovedstaden" which is the region with the capital and its suburbs is the largest region measured in number of citizens and number of municipalities and at the same time the region which is most densely populated. Data on uptake eleven months prior to and one month after the effectuation of the law was mapped and combined with data on media coverage in local newspapers in the same period. The media base InfoMedia which indexes all public media was used to identify communication on the Digital Post in local newspapers. The search criteria used in the InfoMedia base was any article within a given week where the words "Digital Post" appeared. The argument for using local newspapers in the analysis is their em- 
beddedness in the local context. Their content apart from local advertisements is mainly news and announcements to the local community. Furthermore, the reasons for choosing the local newspapers for the analysis were: i) it is freely distributed; ii) to all households; iii) it is assumed that it has a larger number of readers compared to subscription newspapers; and finally iv) it gives an opportunity to analyze where and when information about the Digital Post was communicated. Data on the local communication was collected on a weekly basis for each of the Danish regions. A total of 1.222 articles which met the search criteria were published during the period 1.11.2013 to 30.11.2014.

Table 2. Basic information about the five Danish regions

\begin{tabular}{|l|r|c|}
\hline Region & $\begin{array}{l}\text { Share of population }+15 \text { years } \\
(\mathrm{n}=4.692 .381)\end{array}$ & Number of Municipalities \\
\hline Hovedstaden & $31,23 \%$ & 29 \\
\hline Sjælland & $14,54 \%$ & 17 \\
\hline Sydjylland & $21,32 \%$ & 22 \\
\hline Midtjylland & $22,52 \%$ & 19 \\
\hline Nordjylland & $10,39 \%$ & 11 \\
\hline Total & $100 \%$ & 98 \\
\hline
\end{tabular}

The articles were registered per region and were mapped against the percentage of citizens which had actively signed up for digital post across the regions. The numbers are shown in Figures 1-5. The Figures show that there is a steady growth in number of citizens signing up for the digital post throughout the first eleven months analyzed. For all regions there is a jump in number of citizens enrolled after November $1^{\text {st }} 2014$. The reason for the steep increase is that citizens who did not sign up voluntary were automatically enrolled by November $1^{\text {st }}$ unless they had actively opted out. It is beyond the scope of this analysis to discuss this phenomenon.

The initial analysis of numbers and graphs delivers a mixed message:

a) media does not influence uptake, and

b) media influences uptake.

\subsection{Ad a) media does not influence uptake:}

Figures 1-5 show a steady and similar growth in enrollments in all regions. The steady growth and level of uptake is independent of the media coverage in local newspapers. Region Nordjylland (Figure 5) published sparsely in local media whereas Region Hovedstaden and Region Sjælland (Figure 1-2) much more frequently published information about the Digital Post (notice that the measures on the y-axis differ across the regions). This pattern corresponds to a study of the uptake of Digital Post among citizens in 2012-13 by Berger and Hertzum [3]. This suggests that the hypodermic model $[9 ; 24]$ was of little use in relation to the enrollment of citizens to Digital Post when taking into consideration that the diffusion curve had an almost identical trajectory in all five regions independently of local media exposure. 


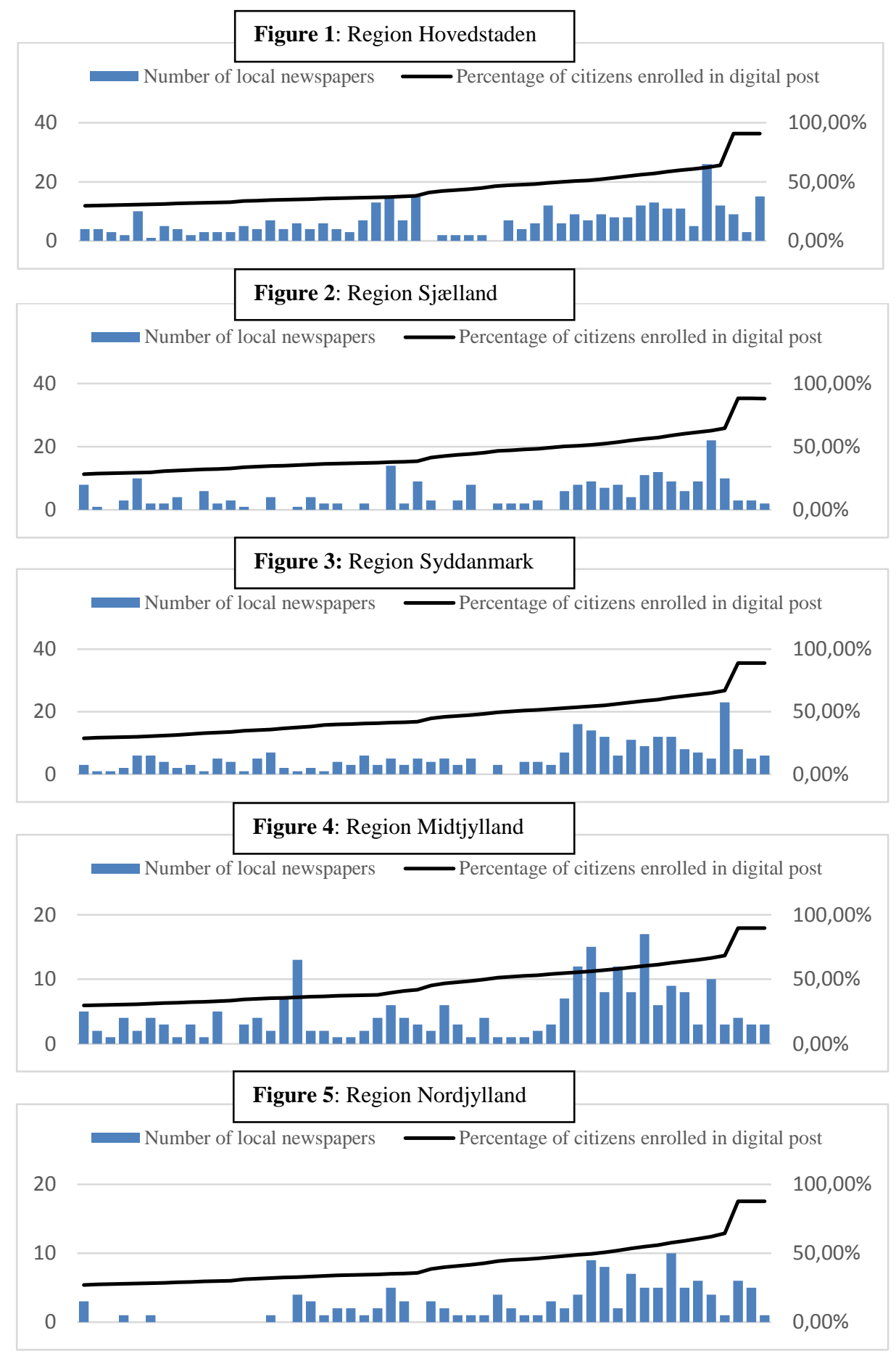




\subsection{Ad b) media influences uptake:}

Figure 1-5 show that there is a simultaneous increase in enrollment across all regions in week 22 (May 2014). What is remarkable is that there is an increase in number of articles in week 20. This could indicate that readers of the local newspapers have been influenced by the media coverage. The increase in enrollments from week 21 to week 22 is statistical significant (Chi-square statistics: $\mathrm{p}<0.01$ ).

Figure 6. All regions all articles

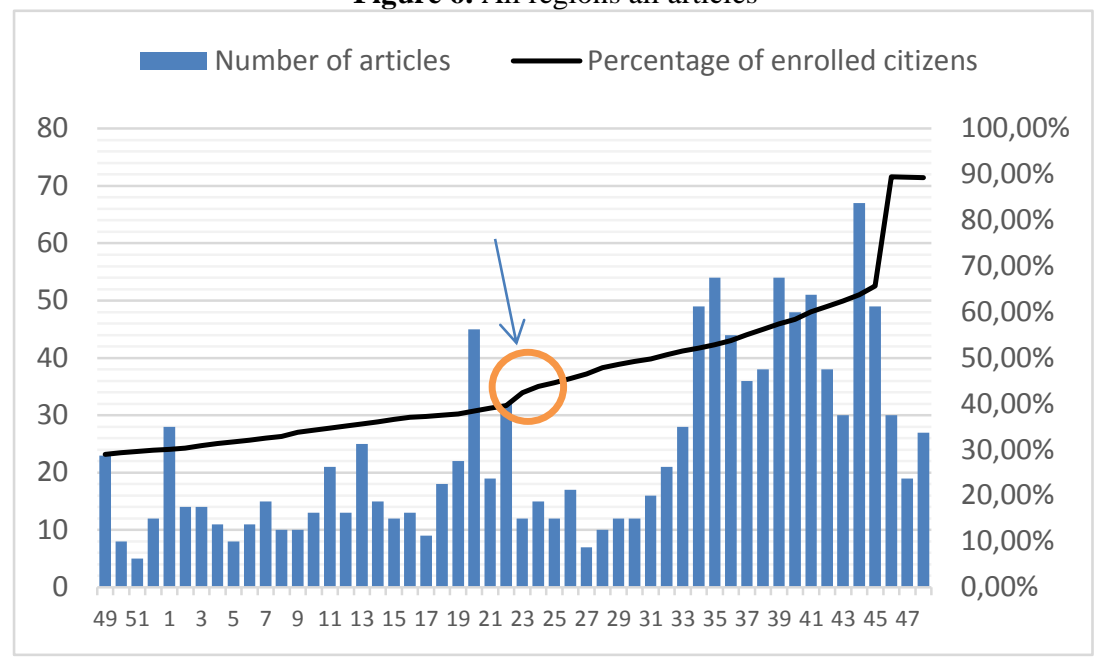

To get further insight to the actual media communication in week 20 and to find frames related to Digital Post we now turn to content of the articles published in local media during that particular week compared to other weeks. There were 45 articles on Digital Post in local newspapers in week 20. To identify differences in the media communication prior to week 20 and after week 20 the 1.222 articles were analyzed using one of the simple text-filtering tools (WordItOut) available on-line. The 30 most frequent nouns, adjectives, and verbs were included. Given that the texts are in Danish the outcome of the analysis is presented as tag clouds to illustrate the three groups of texts.

Irrespective of the large variation in number of articles it is striking that the tag clouds do not differ significantly in their composition in the three clusters. From week 20 the words Digital and Post have a more prominent position. The word "fritagelse" which translates into opting out does appear in the week 20 tag and not in the prior weeks of media coverage. This should however lead to that less people sign up for the Digital Post in the following weeks. The tag clouds illustrate that communication has been rather consistent throughout the period analyzed. However, there is one shift which is noticed from browsing through the three clusters of articles. Up to week 20 there is mainly focus on getting the elderly on board. From reading the articles it shows that in particular headings of articles are designed to get the attention of elderly citizens. "Workshops for elderly", "Assistance for elderly", "Help to IT-disabled" and 
similar headings are found across the articles relating to Digital Post. The articles after week 20 do however recognize that youth is the most challenging group to get on board.

Figure 7: Tag clouds of articles

\begin{tabular}{|c|c|c|}
\hline Before week $20(n=380)$ & Week $20(n=45)$ & After week $20(n=847)$ \\
\hline 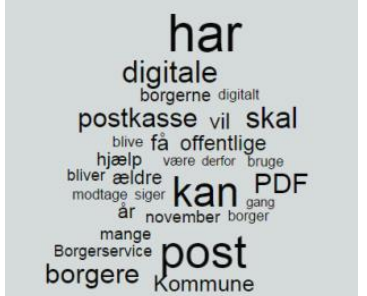 & 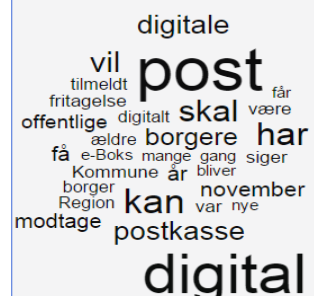 & 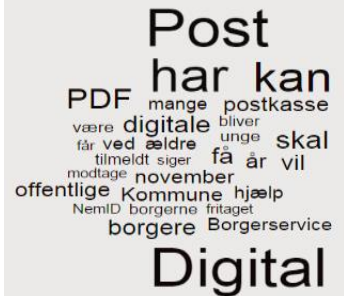 \\
\hline
\end{tabular}

A cross-check in the InfoMedia base in relation coverage on Digital Post in National and Regional newspapers in week 20 shows a different pattern. National newspapers had only 3 articles the particular week and Regional newspapers had 24 articles. The coverage in Regional newspapers differs substantially from the local coverage. The Regional newspapers have in general very negative headings e.g. "Digital terror", "Digital disadvantages", and "More Citizens will opt out". The majority of articles are letters to the editor where citizens air their frustration. In comparison do the Local newspapers have headings such as "Join the Internet cafe"" and "Workshop on Digital Post", reflecting a helpful and cozy atmosphere. The articles are with no exception written by the journalists affiliated with the newspapers.

To get a closer understanding of the content of the media coverage in local newspapers the next step is to identify the framing of Digital Post. First of all it is striking to see how well the overall campaign is infused in the local media is across the 98 Danish municipalities. The message is homogeneous across the 1.222 articles with a similar lexical choice [11] leading to similar framing across time and regions. The framing across municipalities and their respective local outlets leave little room for interpretation. Though it is possible to identify counter arguments in the public debate from the Regional newspapers the overall framing presented in the Local newspapers is consistent over time. It is a framing which is not questioning the phenomenon of Digital Post. Instead the campaign establishes a competition where municipalities encourage citizens to enroll to help the municipality to win the race. A large number of municipalities even chose to introduce a prize for signing up for the digital post-box. There were identified 120 articles which encouraged citizens to sign up for Digital Post and thus be part of a prize draw. In the time-spirit and in line with the overall goal of digitizing the prize was an iPad. 
Table 3. Digital Post frames

\begin{tabular}{|l|l|}
\hline Framing devices & How to think about the issue \\
\hline Metaphors & $\begin{array}{l}\text { The same just more convenient. } \\
\text { Digital Post is more secure and much easier. } \\
\text { Paper-based letters get replaced with digital messages. }\end{array}$ \\
\hline Exemplars & ".a. \\
\hline Catchphrases & $\begin{array}{l}\text { With Digital Post can you read messages from public sector - } \\
\text { independently of location. You get rid of paper and binders, and } \\
\text { your letters never get lost. }\end{array}$ \\
\hline Depictions & $\begin{array}{l}\text { eGovernment is difficult to com- } \\
\text { municate via visual images. But the } \\
\text { Agency for Digitization has de- } \\
\text { signed an image which has been } \\
\text { shown everywhere. The image has } \\
\text { similarities to an Apple product } \\
\text { and almost gives the silky feel of } \\
\text { the packaging of Apple products. }\end{array}$ \\
\hline Reasoning devices & $\begin{array}{l}\text { What should be done about the issue } \\
\text { If you have not yet signed up then attend a workshop where you } \\
\text { learn how to navigate on the Internet and get confident with } \\
\text { technology. }\end{array}$ \\
\hline Roots & $\begin{array}{l}\text { n.a. (municipalities wrote physical letters to all citizens who did } \\
\text { not sign up before November } 1 \text { st and enrolled them automatical- } \\
\text { ly) } \\
\text { ple }\end{array}$ \\
\hline Consequences
\end{tabular}

Adapted from Gamson and Modigliani [10]

The analysis on citizen enrollment to Digital Post solely focused on the weekly increase at regional level. The open dataset is much richer with data on the individual municipality including gender, age and socio-economic status of citizens enrolled. The superficial use of the data-set does however illustrate the potential for gaining insights and showing trends on eGovernment uptake. But does it tell the full story?

\section{$5 \quad$... and some reflections}

In their essay on deconstruction of IS texts Chiasson and Davidson [5] raises the question of the practical relevance of scrutinizing texts. Their answer to the question is that breakthrough innovations often require the overturning of the taken-for-granted assumptions. The taken-for granted assumption in the case of Digital Post as it is pre- 
sented in local media is that Digital Post is a positive step towards e-government implementation, which is positive too.

The data used to illustrate the case of uptake of Digital Post is based on a quantitative open government data-set including the total population combined with qualitative data from the open archives of the Parliament and on-line information from the Agency of Digitization. As stated in the introduction the primary objective of this paper is to "initiate a discussion about the potential of using open government data-sets in (eGovernment) research." The quantitative open data-sets often excel by including the total population contrary to the situation where research is based on sampling and methodological stances of the researcher in charge of designing the instruments for data collection. And it is beyond discussion that the openness "enable public access and facilitate exploitation" [15]. But do they make field research obsolete? The sources included in the paper illustrate the richness in open government data but also the potential for multiple interpretations which are highly dependent on specific knowledge about the context. The highly interpretative framework on media frames [10] was added to illustrate that we can scrutinize open government data and get parts of the story on uptake but to understand patterns in eGovernment uptake we still need a contextual qualitative data which need a human (researchers') touch in order to make sense of the massive body of information generated by public sector institutions.

\section{References}

1. Agency of Digitization. Open data-set on citizen enrollment: https://www.borger.dk/formyndigheder/Sider/Kampagnematerialer-2014.aspx?NavigationTaxonomyId=fa911c07f84c-4def-8218-6d52a8200433 (accessed March 2015)

2. Berger, J B (2014). Mandatory e-government has arrived: The silent protest from staff calls for the committed scholar - resistance must never be futile! In Proceedings of The 25th Australasian Conference on Information Systems (ACIS), Auckland.

3. Berger, J. B., \& Hertzum, M. (2014). Adoption Patterns for the Digital Post System by Danish Municipalities and Citizens. In Proceedings of The Twenty Second European Conference on Information Systems (ECIS), Tel Aviv.

4. Belanger \& Carter (2009) The Impact of The Digital Divide on E-Government. Communications of the ACM, vol. 52(4), pp. 132-135.

5. Chiasson, M. \& Davidson, E. (2012). Reconsidering deconstruction in information systems research. European Journal of Information Systems, vol. 21(2), pp. 192-206.

6. Coursey, D., \& Norris, D. F. (2008). Models of e-government: Are they correct? An empirical assessment. Public Administration Review, 68(3), 523-536.

7. De Vreese, C. H. (2005). News framing: Theory and typology. Information design journal+ document design, 13(1), 51-62.

8. E-government strategy (2011) e-government strategy 2011-15, http://www.digst.dk/Servicemenu/English (accessed March 2015).

9. Gamson, W. A. (1988). The 1987 distinguished lecture: A constructionist approach to mass media and public opinion. Symbolic interaction, 11(2): 161-174.

10. Gamson, W. A. \&; Modigliani, A. (1989). Media discourse and public opinion on nuclear power: A constructionist approach. American journal of sociology, pp. 1-37. 
11. Hansen, A. (2011). Communication, media and environment: Towards reconnecting research on the production, content and social implications of environmental communication. International Communication Gazette, 73 (1-2): pp. 7-25.

12. Helbig, N., Ramón Gil-García, J., \& Ferro, E. (2009). Understanding the complexity of electronic government: Implications from the digital divide literature. Government Information Quarterly, 26(1), pp. 89-97.

13. Jaeger, P. T., \& Bertot, J. C. (2011). Responsibility rolls down: Public libraries and the social and policy obligations of ensuring access to e-government and government information. Public Library Quarterly, 30(2), pp. 91-116.

14. Janssen, K. (2011). The influence of the PSI directive on open government data: An overview of recent developments. Government Information Quarterly,28(4), pp. 446-456.

15. Kalampokis, E., Tambouris, E., \& Tarabanis, K. (2011). A classification scheme for open government data: towards linking decentralised data.International Journal of Web Engineering and Technology, 6(3), pp. 266-285.

16. Kraemer, K., \& King, J. L. (2006). Information technology and administrative reform: will e-government be different? International Journal of Electronic Government Research (IJEGR), 2(1), pp. 1-20.

17. Kvasny, L. \& Truex, D. (2001). Defining away the digital divide: A content analysis of institutional influences on popular representations of technology. In: Realigning Research and Practice in Information Systems Development. Springer US, pp. 399-414.

18. McNeal, R. S., Tolbert, C. J., Mossberger, K., \& Dotterweich, L. J. (2003). Innovating in Digital Government in the American States*. Social Science Quarterly, 84(1), pp. 52-70.

19. Norris, P. (2001). Digital divide: Civic engagement, information poverty, and the Internet worldwide. Cambridge University Press.

20. Norris, D. F., \& Reddick, C. G. (2013). Local EGovernment in the United States: Transformation or Incremental Change? Public Administration Review,73(1), pp. 165-175.

21. Olsson, T. (2006). Appropriating civic information and communication technology: a critical study of Swedish ICT policy visions. New Media \& Society, 8(4), pp. 611-627.

22. Pan, Z. \& Kosicki, G. M. (1993). Framing analysis: An approach to news discourse. Political communication, 10(1), pp. 55-75.

23. Reuters (2014) REUTERS INSTITUTE DIGITAL NEWS REPORT 2014 https://reutersinstitute.politics.ox.ac.uk

24. Rogers, E. M. (2003). Diffusion of Innovations, Free Press, New York.

25. Selwyn, N. (2009, July). The digital native-myth and reality. In Aslib Proceedings, 61(4) pp. 364-379.

26. Venkatesh, V., Chan, F. K., \& Thong, J. Y. (2012). Designing e-government services: Key service attributes and citizens' preference structures. Journal of Operations Management, 30(1), pp. 116-133.

27. Yildiz, M. \& Saylam, A. (2013). E-government discourses: An inductive analysis. Government Information Quarterly. 30(2), pp. 141-153. 